\title{
Comparison of One-Step and Multistep Polishing Systems for the Surface Roughness of Resin Composites
}

\author{
Ismail Hakkı Baltacıoğlu1, Ozgur Irmak², Nuran Ulusoy³, Esra Cengiz ${ }^{3}$, \\ Yıldırım Hakan Bağıș ${ }^{1}$ \\ ${ }^{1}$ Department of Restorative Dentistry, Faculty of Dentistry, Ankara University, Ankara, Turkey \\ ${ }^{2}$ Department of Restorative Dentistry, Faculty of Dentistry, Osmangazi University, Eskisehir, Turkey \\ ${ }^{3}$ Department of Restorative Dentistry, Faculty of Dentistry, Near East University, Mersin, Turkey \\ Email: nuranulusoy@gmail.com,dtesracengiz@yahoo.com
}

Received 1 February 2016; accepted 19 March 2016; published 22 March 2016

Copyright (C) 2016 by authors and Scientific Research Publishing Inc.

This work is licensed under the Creative Commons Attribution International License (CC BY). http://creativecommons.org/licenses/by/4.0/

(c) (7) Open Access

\begin{abstract}
Aim: This study analyzed the effect of different finishing and polishing systems on the surface roughness of a microfilled (Amaris), and a nanofilled resin composite (Clearfil Majesty Esthetic) using Scanning electron microscope (SEM) analysis and surface roughness tester. Materials and Methods: Thirty five specimens of each material were prepared in a plexiglass mold $(10 \mathrm{~mm}$ in diameter and $2 \mathrm{~mm}$ in depth) and cured against a Mylar matrix strip to create a baseline surface. The average surface roughness was measured using a surface profilometer (Mahr Perthometer SP4, Germany) in three different positions on each sample before and after finishing with one of the seven finishing procedures: Procedure 1: Mylar strip (control), Procedure 2: Tungsten carbide burs, Procedure 3: Diamond burs, Procedure 4: Procedure $2+$ one-step diamond micropolisher (PoGo), Procedure 5: Procedure $2+$ multi-step discs (Super-snap), Procedure 6: Procedure 3 + one-step diamond micropolisher (PoGo), Procedure 7: Procedure $3+$ multi-step discs (Supersnap). The obtained data were analyzed using two-way analysis of variance (ANOVA) and Duncan test at a $\mathbf{p}=\mathbf{0 . 0 5}$ significance level. Results: Nanofilled composite showed significantly lower Ra values than microfilled composite in procedures 4,6 and $7(\mathrm{p}<0.05)$. In other procedures, there were no significant differences among composites $(p>0.05)$. Conclusion: Nanofilled resin composite showed significantly lower Ra values than microfilled resin composite. Regardless of finishing methods, diamond micro-polisher produced smoother surfaces than polishing discs.
\end{abstract}

\section{Keywords}

Surface Roughness, Resin Composites, One-Step Polishing

How to cite this paper: Baltacıoğlu, I.H., Irmak, O., Ulusoy, N., Cengiz, E. and Bağış, Y.H. (2016) Comparison of One-Step and Multistep Polishing Systems for the Surface Roughness of Resin Composites. Open Journal of Stomatology, 6, 73-80. 


\section{Introduction}

Recent advancements in the filler technology have improved the mechanical and physical properties of novel resin composites and gave way to restorations that closely resemble the natural tooth structures. Microfilled composites have less inorganic content with a smaller filler particle size than hybrid and packable composites. In recent years, nanofilled resin composites were developed after the advances in the field of nanotechnology. Nanofilled restorative materials have the combined advantage of hybrid and microfilled resin composites and have higher surface quality and high strength in anterior and posterior restorations.

Surface quality is important to enhance both esthetics and the longevity of restored teeth [1]-[3]. Surface roughness of resin composites results in excessive plaque accumulation, gingival irritation, increased surface staining, and poor gloss of the restored teeth [4] [5]. Resin composite materials are available with a variety of filler types that affect their handling characteristics and physical properties. Due to the different hardness of the resin matrix and the inorganic filler, homogeneous abrasion and a well finished and polished surface is difficult to obtain [6]. Proper finishing and polishing of dental restorations are important aspects of clinical restorative procedures. Improper finishing and polishing can result in clinical problems for both the patient and the clinician. Efforts have been made in previous studies, to obtain the best surface finish for traditional resin composites. The smoothest surfaces were obtained with a clear Mylar matrix [7] [8]. On the other hand, resin composite surfaces finished with a Mylar matrix exhibit a resin rich surface layer, which may easily abrade in the oral environment, and unpolished, rough, and inorganic filler material can be exposed [9].

A variety of instruments are used for finishing and polishing resin composites including: carbide (8 - 12 - 16 and 30 fluted) and diamond (25 - $50 \mu \mathrm{m})$ finishing burs, abrasive strips, abrasive impregnated rubber cups and points, aluminum oxide coated abrasive discs, and polishing pastes [4] [8]-[10]. In previous studies, each of these instruments or devices has left the surface of various restorative materials with varying degrees of roughness when compared with their unfinished counterparts [1] [4] [7] [10]-[15]. Although these surface defects have been considered only minimal the extent to which such damage contributes to surface roughness of composites is unknown. Therefore, it is still unclear whether the instrument of choice for finishing and polishing may substantially affect surface roughness of novel resin composites.

This study aimed to evaluate the effect of different finishing and polishing instruments on the surface roughness of a microfilled and a nanofilled composite restorative material. First, null hypothesis tested was filler type which would not affect the surface roughness of composite material. Second, null hypothesis tested was finishing and polishing methods which would not affect the surface roughness of composite material.

\section{Methods and Materials}

The experimental design in this study had a factorial $2 \times 7$ array with 5 experimental units per treatment. Factors examined comprised: 1) resin composite at 2 levels: a microfilled resin composite (Amaris, Voco GmbH, Cuxhaven, Germany, LOT \# 0801254) (AMR) and a nanofilled resin composite (Clearfil Majesty Esthetic, Kuraray Co. Ltd., Osaka, Japan, LOT \#00004B) (CME) and 2) finishing/polishing protocol at 7 levels as indicated in Table 1. Materials used for finishing and polishing of composites are shown in Table 2.

Thirty five circular shaped specimens for each composite type were prepared in a plexiglas mold, $2 \mathrm{~mm}$ thick $\times 10 \mathrm{~mm}$ in diameter. While in contact with Mylar matrix strips (Hawe-Neos Dental, Bioggio, Switzerland) and placed between two $1 \mathrm{~mm}$ thick glass slides, the specimens were light cured for $20 \mathrm{~s}$ using a quartz tungsten halogen Hilux light (Benlioglu Dental A. S. Ankara, Turkey) provided that tip of the curing unit was in contact with the topmost surface of the glass slide. The intensity of the light curing unit was checked using a Hilux curing light meter (Benlioglu Dental A. S. Ankara, Turkey) before starting the polymerization. The mean output was $900 \mathrm{~mW} / \mathrm{cm}^{2}$. After the irradiation, matrix strips were discarded and specimens were stored in distilled water at $37^{\circ} \mathrm{C}$ for 24 hours. Following the storage period, specimens were randomly divided into 7 groups to receive either one of the finishing and polishing techniques or the control treatment (mylar strip) as follows ( $n=5$ ):

- Procedure 1 (control): No finishing or polishing.

- Procedure 2: Finishing with 12-fluted and 30-fluted tungsten carbide burs, respectively.

- Procedure 3: Finishing with fine, extrafine and ultrafine diamond burs, respectively.

- Procedure 4: After the finishing protocols used in the procedure 2, specimens were polished with diamond coated micro-polishers, PoGo (PG), using a low-speed hand piece with air cooling.

- Procedure 5: After the finishing protocols used in the procedure 2, specimens were polished with fine, and 
Table 1. Methods used for finishing and polishing composites.

\begin{tabular}{cc}
\hline Procedures $(\mathrm{n}=5)$ & Sequence of each finishing/polishing protocol \\
\hline 1 (Control) & Mylar strip \\
2 & 12-fluted + 30-fluted tungsten carbide burs respectively \\
3 & Fine + extrafine + ultrafine diamond burs respectively \\
4 & Procedure 2 + Diamond micro-polisher (PoGo) \\
5 & Procedure 2 + Polishing discs (Super-snap) \\
6 & Procedure 3 + Diamond micro-polisher (PoGo) \\
7 & Procedure 3 + Polishing discs (Super-snap) \\
\hline
\end{tabular}

Table 2. Materials used for finishing and polishing composites.

\begin{tabular}{|c|c|c|c|c|}
\hline Material & Model & GritSize & Manufacturer & Batch \# \\
\hline $\begin{array}{c}\text { 12-fluted } \\
\text { tungsten carbide bur }\end{array}$ & HM 375R 012 & - & $\begin{array}{l}\text { Hager \& Meisinger GmbH, } \\
\text { Neuss, Germany }\end{array}$ & 696586 \\
\hline $\begin{array}{c}\text { 30-fluted } \\
\text { tungsten carbide bur }\end{array}$ & HM 135U & - & $\begin{array}{c}\text { Hager \& Meisinger GmbH, } \\
\text { Neuss, Germany }\end{array}$ & 696376 \\
\hline Fine diamond bur & $862 F 012$ & $27-76 \mu \mathrm{m}$ & $\begin{array}{c}\text { Hager \& Meisinger GmbH, } \\
\text { Neuss, Germany }\end{array}$ & 519319 \\
\hline Extrafine diamond bur & 862C 012 & $10-36 \mu \mathrm{m}$ & $\begin{array}{c}\text { Hager \& Meisinger GmbH, } \\
\text { Neuss, Germany }\end{array}$ & 520219 \\
\hline Ultrafine diamond bur & 862U 012 & $4-14 \mu \mathrm{m}$ & $\begin{array}{c}\text { Hager \& Meisinger GmbH, } \\
\text { Neuss, Germany }\end{array}$ & 650899 \\
\hline Diamond micropolisher & PoGo & - & Dentsply Caulk, Milfor DE, USA & 020507 \\
\hline Fine polishing disc & Super-Snap L501 & - & Shofu Inc., Kyoto, Japan & 0805003 \\
\hline Superfine polishing disc & Super-Snap L502 & - & Shofu Inc., Kyoto, Japan & 0805003 \\
\hline
\end{tabular}

superfine aluminum-oxide abrasive Super-Snap Rainbow polishing discs (SS) respectively.

- Procedure 6: After the finishing protocols used in the procedure 3, specimens were polished with PG.

- Procedure 7: After the finishing protocols used in the procedure 3, specimens were polished with fine, and superfine SS discs respectively.

Each tungsten carbide and diamond bur was used with five back and forth strokes for a total of $20 \mathrm{~s}$ using a high-speed handpiece with air and water cooling. PG and SS were used by light buffing motion for $20 \mathrm{~s}$ using a low speed handpiece under air cooling only. After the use of each disc and bur, tooth surfaces were rinsed and dried before proceeding to the next instrument. Tungsten carbide burs, diamond burs, polishing discs and diamond coated micro-polishers were discarded after each use. Same investigator carried out all specimen preparation, finishing and polishing procedures in order to reduce variability.

After the finishing and polishing procedures were completed, surface roughness of all specimens was measured using a surface profilometer (Mahr Perthometer S4P, Germany). In the sequential mode, each specimen was scanned three times in five different locations across the finished and polished surface. The average of those 15 measurements was used as the outcome value for a given specimen. Average roughness (Ra) was recorded in terms of $\mu \mathrm{m}$. Statistical analysis was performed using two-way analysis of variance (ANOVA) and Duncan test at a $\mathrm{p}=0.05$ significance level.

For SEM analysis; specimens were placed on a rotating table in a high vacuum evaporator and coated with $250 \mathrm{~A}^{\circ}$ of gold. The specimens were then examined with SEM (JSM 6400, JEOL Ltd, Fukuoka, Japan) with a magnification of $\times 500$ at an accelerating voltage of $20 \mathrm{kV}$.

\section{Results}

Table 3 and Figure 1 show the mean surface roughness (Ra) observed with different finishing and polishing 
Table 3. Mean Ra values $(\mu \mathrm{m}) \pm$ standard errors of specimens tested. Same superscript letters indicate no statistically significant difference ( $\mathrm{p}>0.05$ ). Upper cases compare data in the same row and lower cases in the same column.

\begin{tabular}{ccccccccc}
\hline Procedure & $\begin{array}{c}\mathbf{1} \\
\text { (Mylar } \\
\text { strip/control) }\end{array}$ & $\begin{array}{c}\mathbf{2} \\
\text { (Tungsten) }\end{array}$ & $\begin{array}{c}\mathbf{3} \\
\text { (Diamond) }\end{array}$ & $\begin{array}{c}\mathbf{4} \\
\text { (Tungsten/PG) }\end{array}$ & $\begin{array}{c}\mathbf{5} \\
\text { (Tungsten/ } \\
\text { SS) }\end{array}$ & $\begin{array}{c}\mathbf{6} \\
\text { (Diamond// } \\
\text { PG) }\end{array}$ & $\begin{array}{c}\mathbf{7} \\
\text { (Diamond/ } \\
\text { SS) }\end{array}$ \\
\hline Roughness (Ra) & Mean $\pm \mathrm{SE}$ & Mean $\pm \mathrm{SE}$ & Mean $\pm \mathrm{SE}$ & Mean $\pm \mathrm{SE}$ & $\mathrm{Mean} \pm \mathrm{SE}$ & $\mathrm{Mean} \pm \mathrm{SE}$ & $\mathrm{Mean} \pm \mathrm{SE}$ \\
AMR & $\mathrm{Ea}$ & $\mathrm{Ba}$ & $\mathrm{Aa}$ & $\mathrm{Da}$ & $\mathrm{Ca}$ & $\mathrm{Da}$ & $\mathrm{Ca}$ \\
& $0.042 \pm 0.003$ & $0.197 \pm 0.005$ & $0.222 \pm 0.008$ & $0.079 \pm 0.006$ & $0.110 \pm 0.003$ & $0.091 \pm 0.009$ & $0.122 \pm 0.004$ \\
CME & $\mathrm{Ca}$ & $\mathrm{Aa}$ & $\mathrm{Aa}$ & $\mathrm{Cb}$ & $\mathrm{Ba}$ & $\mathrm{Cb}$ & $\mathrm{Bb}$ \\
& $0.043 \pm 0.003$ & $0.221 \pm 0.012$ & $0.227 \pm 0.008$ & $0.055 \pm 0.007$ & $0.097 \pm 0.006$ & $0.055 \pm 0.004$ & $0.102 \pm 0.008$ \\
\hline
\end{tabular}

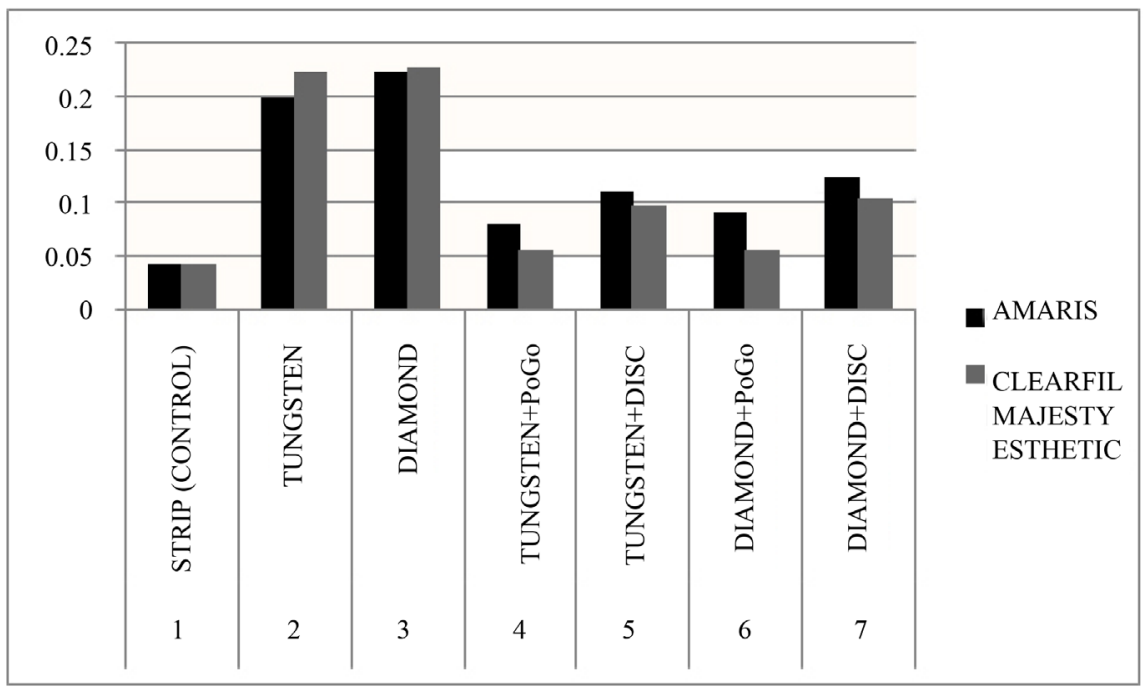

Figure 1. Mean Ra values $(\mu \mathrm{m})$ of resin composites.

procedures. When composite surfaces were finished by mylar strip, diamond or tungsten carbide burs, no significant differences in Ra values were observed between the tested composites, AMR and CME. However, CME showed significantly lower Ra values than AMR ( $<$ 0.05) for Procedures 4, 6 and 7. There were no significant differences between AMR and CME for Procedure 5. For CME; regardless of the finishing method, polishing with PG produced similar surface roughness values with its control group (Mylar strip) (p > 0.05). Comparison of the polishing systems showed that PG produced smoother surfaces than SS for both composites tested (p < 0.05).

In terms of SEM images (Figure 2 and Figure 3), for the two composites; finishing with diamond burs created scratches and deep gouges on the composite surfaces. However, tungsten carbide burs (Figure 2(b) and Figure 3(b)) resulted in irregular but more homogeneous surface finish with less scratches than the diamond bur (Figure 2(c) and Figure 3(c)). Scratches on the two tested composite surfaces polished with SS was probably caused by the edges of the discs during use (Figure 2(e) and Figure 2(g), Figure 3(e) and Figure 3(g)). SEM observations support the findings that the Mylar matrix strip and PG produced smoother surfaces (Figure 2(a) and Figure 3(a)).

\section{Discussion}

First null hypothesis of the study was partially rejected, since there were differences between composites for some of the procedures employed. Second null hypothesis had to be rejected since finishing and polishing methods affected the surface roughness of tested composites. Diamond coated micro-polishers yielded lowest roughness values when compared with other polishing discs.

Surface quality of resin based composite restorations has an important effect on esthetics and longevity of restored teeth [16] [17]. Surface staining, plaque accumulation and gingival irritation might occur due to poor 


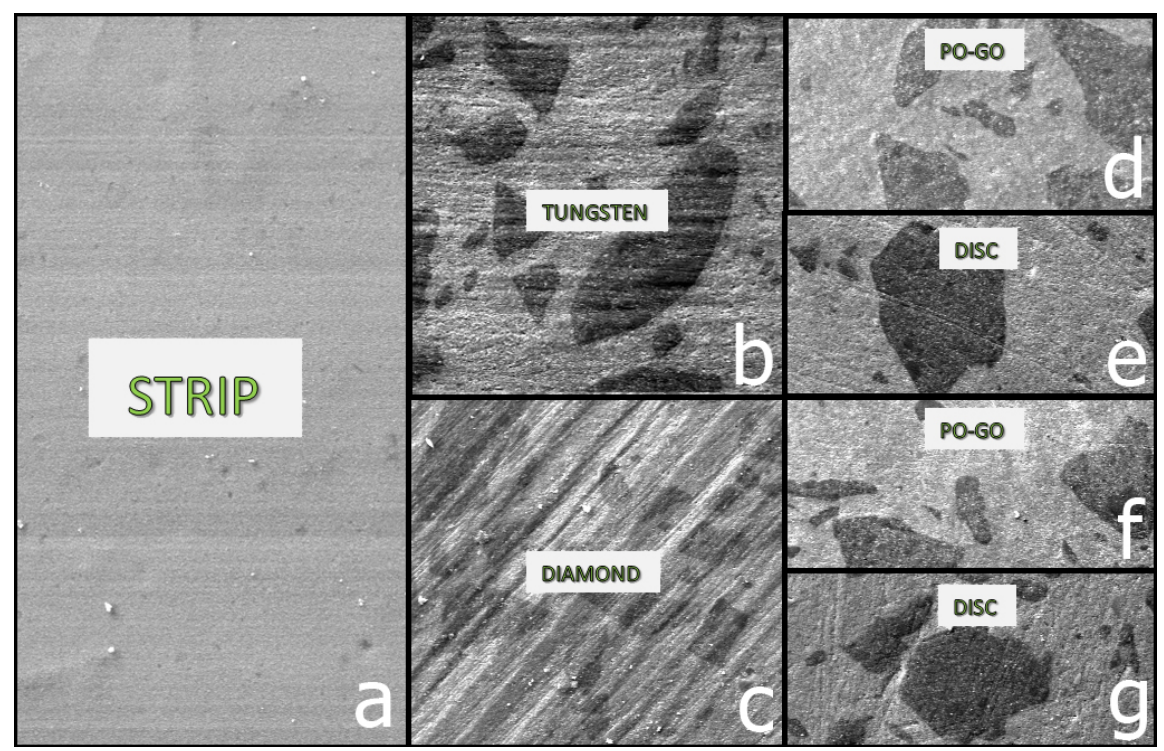

Figure 2. SEM photographs of microfilled composite, AMR (EHT: $20.00 \mathrm{kV}$ Signal A: SE1 Zone Mag: 500×) (a) Procedure 1, (b) procedure 2, (c) procedure 3, (d) procedure 4, (e) procedure 5 , (f) procedure 6 , (g) procedure 7.

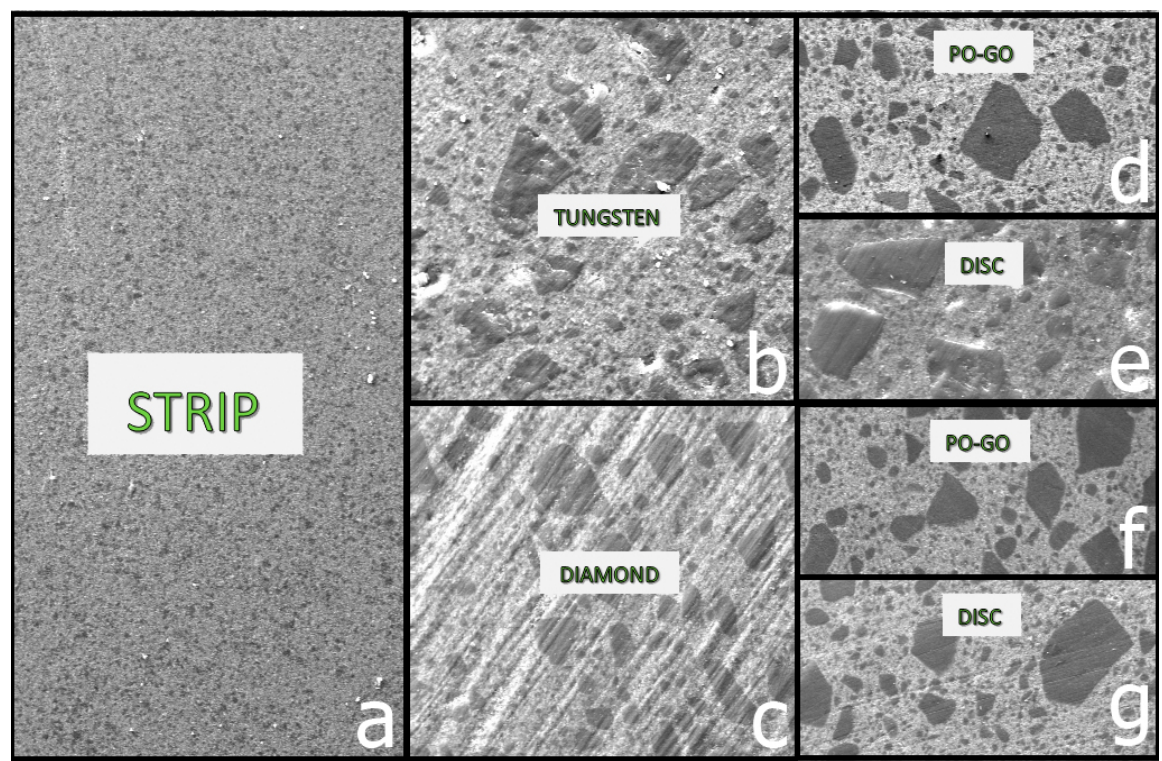

Figure 3. SEM photographs of nanofilled composite, CME (EHT: $20.00 \mathrm{kV}$ Signal A: SE1 Zone Mag: 500×) (a) Procedure 1, (b) procedure 2, (c) procedure 3, (d) procedure 4, (e) procedure 5 , (f) procedure 6 , (g) procedure 7.

surface texture [5] [18]. Surface roughness of restorative materials is measured with a surface profilometer in vitro. The calculated average roughness $(\mathrm{Ra})$ gives numeric values of the surface texture after various finishing and polishing procedures and is helpful to clinicians in their treatment decisions. Lower the value, smoother the surface is. On the other hand; only the use of surface roughness measurements does not fully show the complex structure of a surface, SEM analysis of the surfaces are also done along with the profilometric analyses. In this study, surface roughness measurements were used for relative comparisons. Additionally, changes in the surface texture were examined with SEM.

Polishing procedure becomes complicated in resin composites because of heterogeneous nature of composite matrix and filler particles. In most studies the surface roughness of resin composites after finishing and polishing 
with different protocols are compared with transparent matrices, such as Mylar strips. In the present study, all finishing and polishing procedures showed higher Ra values when compared with control groups and results are in accordance with previous studies [1] [9] [11] [12] [16] [19] [20].

- Polishing: the processcarried out after the finishing and marginations teps of the finishing procedure to remove minutes cratches from the surface of a restoration and obtain a smooth, light-reflective luster. The polishing process is also in tended to produce a homogeneous surface with minimal microscopic scratches and deflects.

Finishing involves removal of irregularities, definition of anatomic conturs and reduction of surface roughness. Polishing, which is performed after finishing, is a procedure to produce a smooth surface with a luster [21]. In clinical procedures, diamond and tungsten carbide burs are used for contouring and finishing both anterior and posterior teeth. The present study showed no significant difference between diamond and tungsten carbide burs for both resin composite. However, finishing with diamond burs created scratches and deep gouges on the surface of both composites. Using tungsten carbide burs with 12 and 30 flutes respectively in the present study resulted in more consistent surface finish with less scratches than the diamond bur in SEM evaluation. This may be attributed to different mechanism of action tungsten carbide and diamond burs. Since tungsten carbide burs have blade like flutes they cut the surface by removing thin layers; contrary to this, diamond burs grind the surface and could make the surface more irregular. Our findings are in agreement with another study that also found more irregular surface with diamond burs [22].

Effects of one-step and multi-step polishing systems on the surface roughness of composites have been reported in literature [3] [9] [11] [12]. There are many different finishing and polishing systems available in the market. The multi-step polishing system (SS) we used in this study has 4 different grit discs, 2 for finishing and 2 for polishing.SS discs are snapped on and secured onto the mandrel by an elastic shank mounted on the discs and do not have metal centers. SEM evaluation in this study revealed scratches on both composite surfaces in groups 5 and 7, probably resulting from the edges of the discs. As sequential use of polishing discs, starting with the coarse grit and continuing with medium, fine and ultrafine discs seems to be time consuming, diamond or silicon carbide coated one-step systems were developed to reduce clinical time and cost. However; PG was found to be the most time consuming method although they resulted in enamel surfaces nearly as smooth as intact enamel [14]. The one-step diamond micropolishers (PG) used in this study are diamond-impregnated polishing devices and designed for use without water cooling in the final polishing of composite restorations. Some investigators reported that specimens polished with PG have lower surface roughness values than multi-step systems [1] [9] [12] [14] [23]-[28]. In accordance with previous studies, PG polishing system used in procedures 4 and 6 showed lower Ra values than SS discs used in procedures 5 and 7 in this study. In the present study, for the nanofilled composite (CME), use of PG after finishing with diamond or carbide bur (procedures 4 and 6) showed no significant difference when compared with control group.

Surface roughness is directly influenced by each resin composite composition and finishing and polishing instrument used. Microfilled composites are used for esthetic restorations because their filler size provides higher polishability than conventional composites containing large filler particles [12] [24]. The application of nanotechnology to composite research is of great benefit [25]. Nanofilled composites contain particles of size below $100 \mathrm{~nm}$ which is important in increasing mechanical properties and reducing polymerization shrinkage. Resin composite, CME tested in this study comprise features of nanotechnology with high filler load and small filler size. Smoother surfaces obtained with CME polished with PG may be attributed to smaller filler size of CME when compared with AMR. Moreover, size of abrasive particles of PG might have been to small to effectively abrade and polish the surface of AMR. We speculate that filler size of CME might be closer to abrasive particle size of PG therefore yielded smoother surfaces. Although filler size is the main parameter for differences in surface roughness of composites, filler type, organic matrix type, silane and degree of conversion may also have effects on surface polishing [29] [30].

\section{Conclusion}

Nanofilled resin composite showed significantly lower Ra values than microfilled resin composite when discs or diamond micropolishers were used after finishing the composite surface with diamond or tungsten carbide burs. When polishing systems were compared; regardless of finishing methods, diamond micro-polisher produced smoother surfaces than polishing discs. The finishing and polishing procedures tested had different effects on 
the surface of the microfilled and nanofilled resin composites. Therefore, the surface roughness of different resin composites after the use of other suitable finishing and polishing systems should be further investigated.

\section{References}

[1] Yap, A.U., Yap, S.H., Teo, C.K. and Ng, J.J. (2004) Finishing/Polishing of Composite and Compomer Restoratives: Effectiveness of One-Step Systems. Operative Dentistry, 29, 275-279.

[2] Jefferies, S.R., Barkmeier, W.W. and Gwinnett, A.J. (1992) Three Composite Finishing Systems: A Multisite in Vitro Evaluation. Journal of Esthetic and Restorative Dentistry, 4, 181-185. http://dx.doi.org/10.1111/j.1708-8240.1992.tb00693.x

[3] Jung, M., Eichelberger, K. and Klimek, J. (2007) Surface Geometry of Four Nanofiller and One Hybrid Composite after One-Step and Multiple-Step Polishing. Operative Dentistry, 32, 347-355. http://dx.doi.org/10.2341/06-101

[4] Jefferies, S.R. (1998) The Art and Science of Abrasive Finishing and Polishing in Restorative Dentistry. Dental Clinics of North America, 42, 613-627.

[5] Shintani, H., Satou, J., Satou, N., Hayashihara, H. and Inoue, T. (1985) Effects of Various Finishing Methods on Staining and Accumulation of Streptococcus Mutans Hs-6 on Composite Resins. Dental Materials, 1, 225-227. http://dx.doi.org/10.1016/S0109-5641(85)80046-4

[6] Pratten, D.H. and Johnson, G.H. (1988) An Evaluation of Finishing Instruments for an Anterior and a Posterior Composite. Journal of Prosthetic Dentistry, 60, 154-158. http://dx.doi.org/10.1016/0022-3913(88)90306-X

[7] Tate, W.H. and Powers, J.M. (1996) Surface Roughness of Composites and Hybrid Ionomers. Operative Dentistry, 21, 53-58.

[8] Wilson, F., Heath, J.R. and Watts, D.C. (1990) Finishing Composite Restorative Materials. Journal of Oral Rehabilitation, 17, 79-87. http://dx.doi.org/10.1111/j.1365-2842.1990.tb01396.x

[9] Korkmaz, Y., Ozel, E., Attar, N. and Aksoy, G. (2008) The Influence of One-Step Polishing Systems on the Surface Roughness and Microhardness of Nanocomposites. Operative Dentistry, 33, 44-50. http://dx.doi.org/10.2341/07-28

[10] Hondrum, S.O. and Fernandez Jr., R. (1997) Contouring, Finishing, and Polishing Class 5 Restorative Materials. Operative Dentistry, 22, 30-36.

[11] Uctasli, M.B., Arisu, H.D., Omurlu, H., Eliguzeloglu, E., Ozcan, S. and Ergun, G. (2007) The Effect of Different Finishing and Polishing Systems on the Surface Roughness of Different Composite Restorative Materials. The Journal of Contemporary Dental Practice, 8, 89-96.

[12] Da Costa, J., Ferracane, J., Paravina, R.D., Mazur, R.F. and Roeder, L. (2007) The Effect of Different Polishing Systems on Surface Roughness and Gloss of Various Resin Composites. Journal of Esthetic and Restorative Dentistry, 19, 214-224. http://dx.doi.org/10.1111/j.1708-8240.2007.00104.x

[13] Kaplan, B.A., Goldstein, G.R., Vijayaraghavan, T.V. and Nelson, I.K. (1996) The Effect of Three Polishing Systems on the Surface Roughness of Four Hybrid Composites: A Profilometric and Scanning Electron Microscopy Study. Journal of Prosthetic Dentistry, 76, 34-38. http://dx.doi.org/10.1016/S0022-3913(96)90343-1

[14] Ulusoy, C. (2009) Comparison of Finishing and Polishing Systems for Residual Resin Removal after Debonding. Journal of Applied Oral Science, 17, 209-215. http://dx.doi.org/10.1590/S1678-77572009000300015

[15] Tate, W.H., DeSchepper, E.J. and Cody, T. (1992) Quantitative Analysis of Six Composite Polishing Techniques on a Hybrid Composite Material. Journal of Esthetic and Restorative Dentistry, Suppl. 4, 30-32. http://dx.doi.org/10.1111/j.1708-8240.1992.tb00715.x

[16] Turkun, L.S. (2004) Effect of Re-Use of a Disposable Micro-Polisher on the Surface of a Microhybrid Resin Composite. American Journal of Dentistry, 17, 279-282.

[17] Barghi, N. and Lind, S.D. (2000) A Guide to Polishing Direct Composite Resin Restorations. Compendium of Continuing Education in Dentistry, 21, 138-142, 144.

[18] Bollen, C.M., Lambrechts, P. and Quirynen, M. (1997) Comparison of Surface Roughness of Oral Hard Materials to the Threshold Surface Roughness for Bacterial Plaque Retention: A Review of the Literature. Dental Materials, 13, 258-269. http://dx.doi.org/10.1016/S0109-5641(97)80038-3

[19] Baseren, M. (2004) Surface Roughness of Nanofill and Nanohybrid Composite Resin and Ormocer-Based ToothColored Restorative Materials after Several Finishing and Polishing Procedures. Journal of Biomaterials Applications, 19, 121-134. http://dx.doi.org/10.1177/0885328204044011

[20] Ozgunaltay, G., Yazici, A.R. and Gorucu, J. (2003) Effect of Finishing and Polishing Procedures on the Surface Roughness of New Tooth-Coloured Restoratives. Journal of Oral Rehabilitation, 30, 218-224.

http://dx.doi.org/10.1046/j.1365-2842.2003.01022.x 
[21] Jefferies, S.R. (2007) Abrasive Finishing and Polishing in Restorative Dentistry: A State-of-the-Art Review. Dental Clinics of North America, 51, 379-397. http://dx.doi.org/10.1016/j.cden.2006.12.002

[22] Ferracane, J.L., Condon, J.R. and Mitchem, J.C. (1992) Evaluation of Subsurface Defects Created During the Finishing of Composites. Journal of Dental Research, 71, 1628-1632. http://dx.doi.org/10.1177/00220345920710091601

[23] Ozel, E., Korkmaz, Y., Attar, N. and Karabulut, E. (2008) Effect of One-Step Polishing Systems on Surface Roughness of Different Flowable Restorative Materials. Dental Materials Journal, 27, 755-764. http://dx.doi.org/10.4012/dmj.27.755

[24] Scheibe, K.G., Almeida, K.G., Medeiros, I.S., Costa, J.F. and Alves, C.M. (2009) Effect of Different Polishing Systems on the Surface Roughness of Microhybrid Composites. Journal of Applied Oral Science, 17, 21-26. http://dx.doi.org/10.1590/S1678-77572009000100005

[25] Ergucu, Z. and Turkun, L.S. (2007) Surface Roughness of Novel Resin Composites Polished with One-Step Systems. Operative Dentistry, 32, 185-192. http://dx.doi.org/10.2341/06-56

[26] St-Georges, A.J., Bolla, M., Fortin, D., Muller-Bolla, M., Thompson, J.Y. and Stamatiades, P.J. (2005) Surface Finish Produced on Three Resin Composites by New Polishing Systems. Operative Dentistry, 30, 593-597.

[27] Strassler, H. (1990) Polishing Composite Resins to Perfection Depends on the Filler. Dental Office, 10, 9-10.

[28] Paravina, R.D., Roeder, L., Lu, H., Vogel, K. and Powers, J.M. (2004) Effect of Finishing and Polishing Procedures on Surface Roughness, Gloss and Color of Resin-Based Composites. American Journal of Dentistry, 17, 262-266.

[29] Jaarda, M.J., Wang, R.F. and Lang, B.R. (1997) A Regression Analysis of Filler Particle Content to Predict Composite Wear. Journal of Prosthetic Dentistry, 77, 57-67. http://dx.doi.org/10.1016/S0022-3913(97)70208-7

[30] Tanoue, N., Matsumura, H. and Atsuta, M. (2000) Wear and Surface Roughness of Current Prosthetic Composites after Toothbrush/Dentifrice Abrasion. Journal of Prosthetic Dentistry, 84, 93-97. http://dx.doi.org/10.1067/mpr.2000.107560 